\title{
PRE-CONTRACT MATTERS
}

\begin{tabular}{|c|c|c|c|c|c|c|c|}
\hline \multirow[t]{2}{*}{$A$} & \multirow{2}{*}{\multicolumn{2}{|c|}{ SELECTION OF CONTRACTING PARTY }} & 1.01 & & c & Potential binding terms & 1.31 \\
\hline & & & & & & Binding letters of intent & 1.33 \\
\hline \multirow[t]{6}{*}{ B } & \multirow{6}{*}{$\begin{array}{l}\mathrm{ii} \\
\mathrm{iii}\end{array}$} & -CONTRACTUAL DOCUMENTS & 1.06 & iv & & imates & 1.34 \\
\hline & & $\begin{array}{l}\text { Statements of requirements/ } \\
\text { invitations to tender }\end{array}$ & 1.06 & & a & $\begin{array}{l}\text { A cautionary tale: time } \\
\text { estimates in the } B S k y B \text { case }\end{array}$ & 1.37 \\
\hline & & Tenders & 1.14 & & b & A contrast: cost estimates in & \\
\hline & & Letters of intent & 1.21 & & & the $B S k y B$ case & 1.40 \\
\hline & & a 'Non-binding' letters of intent & 1.25 & & c & Lessons for suppliers & 1.44 \\
\hline & & b Agreements to negotiate & 1.27 & & $d$ & Lessons for customers & 1.49 \\
\hline
\end{tabular}

\section{A. SELECTION OF CONTRACTING PARTNER}

The selection of a contracting partner can be crucial to the success of the entire technology project, and one of its 'high risk' stages. The process followed to select a supplier can vary greatly, depending on whether the procuring body is a public or private organisation, and the scale of the project involved. ${ }^{1}$

There are certain key considerations that should be taken into account at the selection stage, regardless of the nature of the tender process. These include:

- has enough thought been given to the detail of what is actually being procured? A thorough understanding of the business need that is intended to be met is essential, and should feed directly into the request for proposal, invitation to tender, or other document that is circulated to potential business partners. Key business stakeholders need to be engaged with and committed to the project. After all, the system is ultimately to be for their use and benefit rather than that of the customer's procurement team.

- does the customer know what the 'solution' looks like, or does it need to develop a solution in tandem with the contracting partner? Whether what is being provided is an existing product or a blue-sky solution (or a

1 Public sector bodies within the UK are subject to public procurement obligations. These are primarily set out in the Public Contract Regulations 2015, SI 2015/102. Specific procurement Regulations may also apply, including the Defence and Security Public Contract Regulations 2011, SI 2011/1848, the Utilities Contracts Regulations 2016, SI 2016/274, and the Concession Contracts Regulations 2016, SI 2016/273. Public procurement rules are, however, outside the scope of this work. 
hybrid of the two) will have an impact on what skills and qualifications are required of the supplier.

- are there key individuals who have been identified as crucial to the project? If so, it is important to ensure at the outset that they are required to be and are involved in the project.

1.03 A decision to select a particular contracting partner will frequently be based on various representations made during a selection process. Where this has happened, it is important to ensure that where those representations are key to the selection of the contracting partner (and therefore relied upon), they are capable of giving rise to an enforceable claim if such representations prove to be false. The most straightforward means of doing so is incorporation within the contract itself, generally in the form of a warranty provision.

1.04 In terms of identifying the contracting partner, prevention is always better than cure. So while obtaining warranties is important from a risk management perspective, proactive checks and due diligence are also crucial. This includes seeking supporting evidence from potential suppliers regarding key statements made, and maintaining a paper-trail of the key information and representations that have been relied on.

1.05 A significant amount of time and work can be spent by the putative contracting parties before a final agreement, with contractual force, is actually reached. Discussions and negotiations during this 'pre-contract' phase are likely to be important for the overall success of the intended project in identifying the parties' expectations, including as to the project's scope, its associated costs and the desired timescale. Typical processes and documents that are generated by the parties during this stage of a nascent project are discussed below. In particular, specific legal risks and challenges that can arise are explored.

\section{B. PRE-CONTRACTUAL DOCUMENTS}

\section{i. Statements of requirements/invitations to tender}

1.06 The first document that is usually created in the pre-contract phase of a project is a 'Statement of Requirements' or an 'Invitation to Tender' (ITT). ${ }^{2}$ The purpose of an ITT is to set out the scope and requirements of the project

2 Which can appear in a number of guises, such as 'Request for Proposal', 'Request for Tender', 'Request for Expression of Interest' and 'Invitation to Quote', etc. 
from the customer's perspective, so as to allow interested suppliers to submit potential solutions.

The customer (or its advisers) will typically prepare the ITT, describing the essential components of the project. The ITT is likely to specify:

- the desired fundamental capabilities and functionality of the required system or solution. Such requirements can vary widely between projects, as can the degree of detail given in the ITT;

- the value of the required system/solution to the customer (which itself is very likely to have been informed by the customer's project business case);

- the expected term of the project (or deadline for implementation);

- information about the customer's business and operations, such as the legacy systems/solutions it has in place, its revenues and strategy for growth. This information indicates to potential suppliers the context in which the required system/solution will need to function (for example, any necessary integration with particular hardware or software used by the customer); and

- the process and timetable of the contract award process, including dates of any submission deadlines and the procedure for potential suppliers to seek clarifications about the project.

There are evident advantages for all parties in the use of an accurate and comprehensive ITT. At the early tendering stage, it will often serve as the main driver behind technical discussions and allows parties to estimate the likely timeframe and costs of a project. ITTs can highlight to a potential supplier the challenges that may need to be overcome in delivering the required solution. In this respect, the substance of tenders received will largely be shaped by the content of the ITT; and during the subsequent phases of the pre-contract stage, having the customer's requirements precisely documented may allow parties to identify future priorities, limit the possibility of scope 'creep' and successfully navigate potential disputes.

However, in practice some technology projects may not have the benefit of a truly comprehensive ITT given that, at the early stages, a customer may itself not be certain as to what final solution it needs. Accordingly, to retain some flexibility in its favour, a customer may intentionally describe key concepts and deliverables at a relatively high, broad or vague level. The ITT may also expressly state that the customer has the right to vary its content throughout the procurement process as it sees fit. 
1.10 ITTs are not typically of a binding nature and in the absence of any express or implied term to the contrary will not usually impose obligations on the inviting customer or potential suppliers.

1.11 In particular older case law indicates that a party inviting tenders will not be under an obligation to accept (or, indeed, even consider) any tender received, except where the ITT itself demonstrates an intention that this should be so. In Spencer v Harding, ${ }^{3}$ Willes J found a circular inviting tenders to be a 'mere attempt to ascertain whether an offer can be obtained within such a margin as the sellers are willing to adopt'.

1.12 More recent case law has shown the importance of considering the possible construction of the content of the ITT, particularly when setting out the process for tender submissions. For example, in Blackpool and Fylde Aero Club Ltd $v$ Blackpool Borough Council, ${ }^{4}$ the Court of Appeal held that it was an implied term of an ITT in that case that there was an obligation on the customer to consider any and all compliant submissions made before the deadline. The ITT itself expressly stated only that late responses would not be considered. In Harvela Investment Ltd $v$ Royal Trust Company of Canada (C.I.) Ltd and Others, ${ }^{5}$ the House of Lords conducted a wider exercise in assessing the parties' intentions to determine whether, in the absence of express wording, the terms of the customer's ITT allowed for referential bids to be made (i.e., where an offer is expressed as ' $\mathrm{Ex}$ higher than any competitor's bid'). The customer was bound by its ITT to accept the highest offer, although it was found that the inclusion of a confidentiality clause, the design of the process to create a level playing field for the highest bids and the lack of any wording detailing the mechanisms of a referential bidding process showed the intended process was one of fixed bids. It follows that it is important to consider not only the effect of those terms obviously related to the tendering process, including any clauses excluding or limiting liability or creating an obligation to consider tenders fairly or at all, but also the wider context in which those terms are intended to operate.

1.13 Some aspects of an ITT may eventually form a central part of the final agreed contract, for example as a schedule setting out the customer's requirements. In such circumstances, the parties should ensure that its contents define precisely the proper scope of the project requirements and are carefully reviewed before 
execution of any contract incorporating the ITT. Any broad or vague statements originally made by the customer at the preliminary stage may result in future disagreement if incorporated into a binding contract. Information should be requested by the supplier, subject to agreeing a regime for protecting the confidentiality of the information provided by the customer. As HHJ Thornton QC recognised in Cyprotex Discovery Ltd $v$ The University of Sheffield: 6

in order to draft a specification, it is customary for the programmer to act as an interrogator of the customer in order to extract the precise requirements of the customer. Both parties take an active role in analysing the customer's requirements and the customer will attempt to formulate and reformulate its requirements from the often nebulous concepts that emerge from the programmer's specifications. In turn, the programmer acts both as an interrogator and problem solver.

\section{ii. Tenders}

A tender document sets out the details of how a potential supplier will meet 1.14 the customer's requirements, generally by reference to the requirements specified in the ITT.

Common elements include the following:

- details of the proposed solution/system, including its implementation, set out step-by-step;

- the potential supplier's estimated price, costs and time for delivering the solution. Accuracy and clarity of expected costs at this stage is important. A tender may specify fixed prices for certain stages of, or tasks to be completed under, the proposed project. If so, the tenderer should clearly state what work and materials are included (and excluded) within any fixed price. The importance of estimates submitted during the precontract stage is considered further at paragraphs 1.34-1.51 below;

- information relating to the potential supplier's technical and managerial teams that will be responsible for the proposed solution's implementation and execution; and

- the assumptions upon which the potential supplier has relied in the tender's preparation.

It is for the potential supplier to propose a solution in its tender, based upon the information provided by the customer and any further investigations that 
the tenderer has conducted. Information provided by the customer should not necessarily be taken at face value: even where information provided is misleading, the onus is likely to be on the supplier to evaluate the proposed project and use its expertise and skill to make proposals as to how the project should be performed. ${ }^{7}$ In some instances, a tenderer may consider that a feasible solution requires work not originally contemplated in the ITT, in which case the tender can be used to identify 'incomplete' areas in the customer's requirements.

1.17 On large-scale projects, the submission of tenders can be an iterative process where the customer releases information to potential suppliers in a piecemeal fashion over the course of the procurement phase. This is especially the case where the services being tendered are 'second-generation' and the relevant information is being received from the customer's incumbent supplier.

1.18 A tender is generally regarded as an 'offer' and its acceptance (and the formation of a binding contract) will depend on the terms of the ITT/tender documentation (including, for example, any requirement for (further) formal documentation) and the type of project involved. However, depending on such terms, a successful (i.e., accepted) tender can create a binding legal relationship between the customer and the supplier in certain circumstances. For example, the acceptance by a customer of a tender for a one-off straightforward implementation of hardware may constitute a binding contract, while the acceptance of a tender for the on-going provision of ad hoc services (without formal documentation of the contractual terms) may not. This is, as ever, a matter of construction based on the relevant factual circumstances and context.

1.19 The parties may stipulate that no binding contract will arise prior to formal documentation being executed, as is likely to be the case for the majority of large or complex technology projects. Depending on the size of the project, a tendering party may be less inclined towards starting work before the documents are final, as it may continue to incur costs and time on the project but without any formal assurance that its tender will proceed to a binding agreement. Usually, the costs of tendering will be borne by the tenderer. ${ }^{8}$ Parties should be aware that performance of work on a project (e.g., after a tender has been accepted but before a formal contract has been signed) can

7 See, for example, South West Water Services Ltd v International Computers Ltd [2001] 1 Lloyd's Rep PN 353, 373.

8 William Lacey (Hounslow) Ltd v Davis [1957] 1 WLR 932, although it was recognised that the contractor may be able to recover a reasonable sum for work done at the customer's request which falls outside the 'normal' cost of tendering. See also: British Steel v Cleveland Bridge [1984] 1 All ER 504, 511. 
result in the creation of a binding contract $^{9}$ (as discussed further at paragraphs 3.33 onwards below).

The parties may incorporate the contents of an accepted tender into the final agreed contract, for example, as a schedule setting out the supplier's technical solution. It is also possible that the customer may seek to include any general sales-focused statements made by the supplier in the tender into the final contract, such as statements that the supplier's proposed software solution can meet all of the customer's business requirements and objectives. Suppliers should be wary of these attempts, even if such statements are only referenced in the recitals to a contract, as they may inadvertently create onerous obligations or be relied upon by the customer in the event of a future dispute. While contractual recitals are not typically intended to be binding (unless expressly stated to be so), they may be so in some circumstances or at least may have a significant effect on the construction of key contractual provisions which are ambiguous. ${ }^{10}$

\section{iii. Letters of intent}

Letters of intent ${ }^{11}$ outline the high-level terms of agreement made in principle between the parties, before formal contractual documents are fully negotiated, settled and executed. Generally they are considered to be legally non-binding although, as explained below, a letter of intent (or certain parts of one) can be held to be binding depending on its terms and the precise factual circumstances. In any event, they often provide a degree of comfort to parties during the contract negotiation phase and the parties may even agree that certain principles, such as confidentiality and exclusivity of negotiations, or 'lock-in', are to be binding for a certain period of time leading up to final contract formation.

Circumstances can occur in practice where the parties commence the performance of work or services solely on the basis of a non-binding letter of intent, although for complex technology projects this is generally inadvisable given the uncertainties that can result. In particular, the allocation of risk between the parties on various contractual issues may be unclear and such ambiguity

9 See: RTS Flexible Systems Ltd v Molkerei Alois Muller GmbH \& Co KG [2010] UKSC 14, [2010] 1 WLR 753 and, more controversially (at first instance) The Co-operative Group (CWS) v International Computers Ltd [2003] EWHC 1 (TCC) (reversed on appeal: [2003] EWCA Civ 1955).

10 Re Moon, exp. Dawes (1886) 17 QBD 275, 289 (Lopes LJ).

11 Which are sometimes referred to as 'heads of terms', 'memoranda of understanding' or 'term sheets', although this list of terminology is not exhaustive: see ERDC Group Ltd v Brunel University [2006] EWHC 687 (TCC), [2006] BLR 255, 265. 
may lead to disputes between them (especially if the project does not proceed to completion). ${ }^{12}$

1.23 For large technology projects with a tight timeframe, it may not be practicable for the parties to finalise all of the contractual documents, in which case parties should consider entering into binding agreements relating to certain discrete aspects of the project to enable preliminary work or matters to progress. For instance, planning sessions and the procurement of materials could be agreed separately at the outset. Such discrete contracts or documents can be described as 'binding letters of intent' as they often set out the intention of the parties to enter into a further agreement in due course and to continue negotiating with each other. They should however be treated in the same way as any other formal contract.

1.24 In addition, a binding letter of intent could be used where the customer is unsure whether the technical solution it requires is actually feasible. Therefore, it could decide to commit to pay for technical workshops and planning sessions with the proposed supplier to determine a solution's viability, before committing to the whole project.

\section{a. 'Non-binding' letters of intent}

1.25 Even in non-binding letters of intent there may still be certain provisions that the parties will agree to be binding, such as the protection of confidentiality of certain information which has passed between them. However, it will always be important to consider the usual contractual formation principles (i.e., offer, acceptance, consideration, intention to create legal relations and certainty of terms) to ascertain whether a letter of intent (or certain provisions of the letter of intent) will be considered binding or non-binding.

1.26 If it is intended that the letter of intent should be non-binding, it should specify that it is not legally binding (except perhaps for certain provisions). It should use clear and express language as to which terms are intended to be binding and which are not and usually the document will be expressed to be 'subject to contract'. A governing law and jurisdiction provision should also be incorporated (particularly if the parties are of different nationalities). Typical clauses that parties may wish to be binding are discussed further below.

12 See further paras 3.21 onwards below. 


\section{b. Agreements to negotiate}

Both non-binding and binding letters of intent may expressly state that both

parties 'agree to work towards completing an agreement for the provision of $[\mathrm{x}]$ services as soon as possible' or 'agree to negotiate in good faith a final agreement for the provision of $[\mathrm{x}]$ services' or something similar.

Such an agreement to negotiate is likely to be unenforceable, ${ }^{13}$ meaning there may be little recourse for the innocent party if the other party simply changes its mind about the project and refuses to continue to negotiate. ${ }^{14}$ In Walford $v$ Miles, ${ }^{15}$ the parties had entered into a 'lock-out' agreement whereby the defendants (the owners of a photographic business) were to negotiate with the claimants about selling that business and agreed not to consider proposals from third parties as long as the claimants provided a banker's letter confirming that the bank would provide the claimants with approximately $£ 2$ million to finance the purchase. However, a couple of weeks later, the defendants told the claimants that they had decided to sell to a third party. The claimants alleged that the lock-out agreement was legally enforceable and contained an implied term requiring the defendants to negotiate with the claimants in good faith.

In considering the argument that the lock-out agreement contained an implied term requiring the defendants to negotiate in good faith, the House of Lords held that an agreement to negotiate was unenforceable due to a lack of certainty. ${ }^{16}$ Lord Ackner stated:

The reason why an agreement to negotiate, like an agreement to agree, is unenforceable, is simply because it lacks the necessary certainty ... A duty to negotiate in good faith is as unworkable in practice as it is inherently inconsistent with the position of a negotiating party. It is here that the uncertainty lies. In my judgment, while negotiations are in existence either party is entitled to withdraw from those negotiations, at any time and for any reason. There can be thus no obligation to continue to negotiate

13 At least at this pre-contract stage.

14 An agreement to use best endeavours to negotiate a contract is also unenforceable against the other party: Dany Lions Ltd v Bristol Cars Ltd [2014] EWHC 817 (QB), [2014] 2 All ER (Comm) 403 [20]-[23] and the cases there cited. An agreement to negotiate with a third party may, however, be sufficiently certain to give rise to an obligation: Astor Management AG v Atalaya Mining Plc [2017] EWHC 425 (Comm) [64].

15 [1992] 2 AC 128.

16 Note that an agreement or clause to attempt to agree (in good faith) can be enforceable if contractual machinery also exists which prescribes the means or provides a framework to reach resolution: see, for example, Mamidoil-Jetoil Greek Petroleum Company SA v Okta Crude Oil Refinery AD [2001] 2 Lloyd's Rep 76 [69] (Rix LJ); Cable E Wireless Plc v IBM United Kingdom [2002] EWHC 2059 (Comm), [2003] BLR 89; Tramtrack Croydon Ltd v London Bus Services Ltd [2007] EWHC 107 (Comm); and Emirates Trading Agency LLC v Prime Mineral Exports Private Ltd [2014] EWHC 2104 (Comm), [2015] 1 WLR 1145. 
until there is a 'proper reason' to withdraw. Accordingly a bare agreement to negotiate has no legal content. ${ }^{17}$

1.30 A key factor was that the lock-out agreement was essentially negative in nature (i.e., an agreement not to negotiate with anyone else while negotiating with the claimants). It was discussed that there was no reason in principle why such an agreement could not be legally enforceable for good consideration. In particular, a number of potential good commercial reasons for parties to agree such a term were considered, one being that 'B's property, which A contemplates purchasing, may be such as to require the expenditure of not inconsiderable time and money before $\mathrm{A}$ is in a position to assess what he is prepared to offer for its purchase or whether he wishes to make any offer at all. ${ }^{18}$ However, the problem in Walford $v$ Miles was that the lock-out agreement did not specify how long it was meant to last. It was further argued by the claimants that it should last until the parties, acting in good faith, found themselves unable to reach an agreement but this was rejected as indirectly imposing a duty to negotiate in good faith upon the defendants, which would be unenforceable. ${ }^{19}$

\section{c. Potential binding terms}

1.31 Parties should consider whether they wish the following types of provisions to be binding: ${ }^{20}$

- a clause which itself states that the letter of intent is 'subject to contract';

- confidentiality;

- exclusivity;

- governing law and jurisdiction;

- how costs are to be dealt with in relation to negotiations: it is common for each party to agree to bear its own costs in relation to the negotiation

17 Walford (n 15) 173. Similarly, agreements to use reasonable endeavours to agree or to negotiate in good faith are unenforceable: see Multiplex Constructions UK Ltd v Cleveland Bridge UK Ltd [2006] EWHC 1341 (TCC) [633]-[639]; Barbudev v Eurocom Cable Management Bulgaria EOOD [2012] EWCA Civ 548, [2012] 2 All ER (Comm) 963 [43]-[46]; Shaker v Vistajet Group Holding SA [2012] EWHC 1329 (Comm), [2012] 2 All ER (Comm) 1010 [7]-[18]. Agreements to reach agreement with a third party (such as a financing party) are also unenforceable in the absence of objective criteria by which a court can ascertain whether a party has acted unreasonably: see Scottish Coal v Danish Forestry [2009] CSOH 171 [62].

18 Walford (n 15) 174.

19 Although the English courts have looked more closely at the notion of good faith in commercial contracting in recent years, it is unlikely that the decision would now be decided differently, particularly in light of the parties' relationship being at the pre-contract phase. However, it is possible that an express obligation to negotiate in good faith may not be completely without legal substance: see Petromec Inc v Petroleo Brasileiro SA [2006] 1 Lloyd's Rep 121.

20 This list is not exhaustive and is provided by way of example only. 
of the final contract (and costs to date of negotiating the letter of intent) in the event of a breakdown in negotiations;

- termination of negotiations: a non-binding letter of intent should provide a date of expiry and how that expiry date is to be extended (if required);

- severability of terms;

- how any intellectual property is to be addressed, in the event that any intellectual property has been exchanged before a contract has been signed: for example, how the intellectual property of either party is to be protected from misuse and/or be returned in the event of a breakdown of negotiations;

- how payment in relation to any works commenced before a legally binding contract is signed is to be dealt with: it is generally preferable for the parties to commence work only after a binding contract has been signed either in relation to the whole project or a discrete, preliminary aspect of the project); ${ }^{21}$ and

- entire agreement: any such clause must be clearly drafted in order to exclude liability for negligent or innocent misrepresentation, although it will have no effect in the case of fraudulent misrepresentation in any event.

The types of clauses that parties may wish to remain non-binding until a final contract is executed would include those that are seen to be terms of relevance to the substance of the project. These may include:

- the project milestone or completion dates;

- the contract price for performance of the project;

- the supplier's access to the customer's current systems, premises and/or employees during the project; and

- the required levels of service and associated provisions concerning service level credits and liquidated damages, and any other sections of the letter of intent which relate to allocation of risk between the parties.

\section{d. Binding letters of intent}

If parties agree a binding letter of intent (for example, in relation to an initial stage of a project), then this will operate as a legally enforceable contract. The parties should consider its terms carefully. 


\section{iv. Estimates}

1.34 In a tender, a potential supplier will often provide estimates in relation to the time required to complete the project (or specific stages of the project) and the cost of the proposed solution. Such estimates are important for both suppliers and customers, as they allow both parties to assess whether the project is worth their time and investment before entering into a binding contract.

1.35 In $B S k y B v E D S, 22$ a dispute concerning the implementation of a CRM (Customer Relationship Management) system, ${ }^{23}$ Ramsey J provided a useful summary of the usual 'four stages' of preparing an estimate of time and cost, as follows: ${ }^{24}$

- estimate what work has to be done;

- calculate the resources which are needed to perform that work;

- work out what resources are required to carry out the work within the timeframe required by the customer;

- work out whether those resources are available.

1.36 It is always advisable for suppliers to assess carefully the likely time, resources and cost of delivering the required solution/system for a customer's project. Case law on misrepresentation (including $B S k y B$ ) demonstrates the importance of being able to establish a reasonable belief in the truth of the estimates put forward, meaning that suppliers should aim to carry out full assessments, preferably in close conjunction with the customer, and keep detailed records of the information and analysis supporting the final estimates provided. Unfortunately, there appears to be a tendency for estimates to be overoptimistic or, at worst, misleading, resulting in substantial disputes. ${ }^{25}$

\section{a. A cautionary tale: time estimates in the BSkyB case}

1.37 BSkyB alleged that the defendants, EDS, had made certain representations in response to BSkyB's ITT as to the timing of the delivery of the project, which included an estimated go-live date for a prototype within nine months. The misrepresentations were said to have been made at various stages prior to

BSkyB Ltd v HP Enterprise Services (UK) Ltd (formerly Electronic Data Systems Ltd) [2010] EWHC 86 (TCC), (2010) 26 Const LJ 289, [2010] BLR 267.

23 The facts of which are set out in greater detail at paragraphs 12.10-12.17 below.

$24 B \operatorname{SkyB}(\mathrm{n} 22)[698]$.

25 There has been increasing analysis of project management failures, focusing in part on over-estimation, which is worth reading for background: see, for example, Bent Flyvbjerg of the Said Business School, Oxford University, 'What you should know about Management and Why: An Overview', 2014 45(2) Project Management Journal 6-19; 'Over Budget, Over Time, and Over and Over Again, Managing Major Projects', Ch. 13 in The Oxford Handbook of Project Management (Oxford University Press). 
entering into a letter of intent and prior to entering into the 'Prime Contract'. The precise alleged misrepresentations (as set out in BSkyB's Particulars of Claim) were:

that [EDS] had carried out a proper analysis of the amount of elapsed time needed to complete the initial delivery and go live of the contact centre and that they held the opinion that, and had reasonable grounds for holding the opinion that, they could and would deliver the project within the timescales referred to in the Response, and, subsequently, the Contract. ${ }^{26}$

Ramsey J held that the time estimate put forward by EDS contained 1.38 representations which were false: no proper assessment had in fact been carried out by EDS, 27 and the estimate was based on assumptions rather than proper analysis. The judge specifically noted that EDS' bid team leader had 'confirmed that he did not and, as far as he was aware, nobody sought to determine at that stage what work was required to be done in the first nine months in order to achieve go-live within that period'. ${ }^{28}$

Given BSkyB's clearly stated desire to complete the project in a short timeframe, Ramsey J was prepared to find that BSkyB had relied upon EDS' time estimate and had been induced by it to enter into both the Letter of Intent and the Prime Contract.

\section{b. A contrast: cost estimates in the BSkyB case}

While it may be tempting for a potential supplier to offer a low cost estimate in order to secure a contract (or to promise to meet the budget as set out in the customer's ITT), the same principles discussed above concerning time estimates apply equally to cost estimates.

In $B S k y B$, EDS had stated that it would provide a contact centre 'on time and on budget' and would 'meet the financial and budgetary targets that you $[B S k y B]$ have set'.

Ramsey J heard evidence from EDS' bid team leader that the cost estimate was calculated by EDS' bid team in at least two half-day sessions (plus other meetings) and that they looked at a 'bottom up estimate from expected functionality' and a “top down” estimate to provide a measure of verification'. ${ }^{29}$

27 Note that the misrepresentation did not arise because the estimates had not been met: a statement as to the future is likely to be interpreted as a statement concerning the maker's currently held opinion or intention.

28 BSkyB (n 22) [783].

29 Ibid. [702]. 
The conclusions made were then recorded in a costings spreadsheet. In essence, a 'bottom up' estimation meant working through a project from beginning to end and tallying up the likely costs step-by-step. In contrast, the 'top down' approach involved an analysis of the broad aspects of the project and estimating the costs based on the time required and previous costs on past (similar) projects. There was supporting documentation demonstrating the general process EDS followed, such as notes of associated workshops and de-briefings, while BSkyB's expert confirmed that he considered the 'top down' and 'bottom-up' methodologies to be acceptable processes of estimation.

1.43 The court considered that EDS had represented to BSkyB that a proper estimate of cost had been carried out, together with the proper investigations, and that EDS had reasonable grounds for believing the project could be delivered within that estimated budget.

\section{c. Lessons for suppliers}

1.44 Estimates need to include proper assumptions and caveats, together with a discussion of the reasonableness of such assumptions and caveats. Such assumptions and caveats should be brought to the attention of the customer and not hidden in small print.

1.45 Suppliers should consider how much cooperation they will need from the customer in order to meet the required deadlines and budgets. Such details should be expressed in the estimate itself. For example, for a project involving the design and development of a mobile application, the customer may need to provide all of the visual designs for the 'look and feel' of the product before other work on development can commence. Delays from the customer in providing such designs will inevitably have a knock-on effect on timings and cost and - accordingly - the consequences of delays caused by the customer (or a general lack of cooperation) will have to be considered. There is a particularly strong focus on the need for customer and supplier cooperation in 'agile' projects, where personnel of both parties work side by side on each 'sprint' phase. ${ }^{30}$ In any event, effective collaboration is important for the success of more traditional 'waterfall' projects as well.

1.46 Suppliers should keep full records of the analysis carried out in order to prepare time, costs and resources estimates and be satisfied that the analysis is robust and can be supported by documentary evidence.

30 See also paras 3.08-3.18 below. 
Suppliers should also consider whether estimates should be prepared collaboratively by members of the supplier's sales team, legal team and the team who will actually be implementing/executing the solution (for example, the day-today developers and programmers). This will help to ensure that the different priorities of each of these teams are well-balanced, with the aim that a sufficiently robust estimate can be delivered to the customer.

During post-tender meetings or site visits, a supplier may identify areas in which additional or different work is required to that originally contemplated in the ITT (or tender). Ideally, such 'gaps' should be identified as early as possible in the lifetime of a project so that the relevant requirements and solutions can be agreed, discussed and incorporated (including as to time and price) into the final contract as necessary.

\section{d. Lessons for customers}

Customers should be as clear and specific as possible about their requirements. This almost invariably requires the involvement of at least the key business users of the proposed system or application to be involved at an early stage.

Customers should also provide as much information as possible to potential suppliers before asking such suppliers to submit estimates. They should also consider running joint planning sessions with potential suppliers to allow information to be shared and issues to be clarified ${ }^{31}$ and should aim to set realistic budgets and deadlines to reduce the incentive for suppliers to over-promise.

Although there is no 'duty' on the customer to investigate the basis of estimates provided by suppliers in the absence of an express contractual obligation, it is likely to be preferable for customers to satisfy themselves of the viability of estimates at the outset. If meeting a certain deadline is critical to a project, customers should consider recording such timescales as a term of the contract and making 'time of the essence' for that particular phase. ${ }^{32}$

31 There may be restrictions on information sharing in certain circumstances, such as in relation to certain public contract tenders. Such procurement issues are beyond the scope of this work.

32 See paras 10.10-10.16 below. 